\title{
Histone methyltransferases G9a and GLP form heteromeric complexes and are both crucial for methylation of euchromatin at H3-K9
}

\author{
Makoto Tachibana, ${ }^{1}$ Jun Ueda, ${ }^{1}$ Mikiko Fukuda, ${ }^{1}$ Naoki Takeda, ${ }^{2}$ Tsutomu Ohta, ${ }^{3}$ Hiroko Iwanari, ${ }^{4}$ \\ Toshiko Sakihama, ${ }^{4}$ Tatsuhiko Kodama, ${ }^{4}$ Takao Hamakubo, ${ }^{4}$ and Yoichi Shinkai ${ }^{1,5}$ \\ ${ }^{1}$ Experimental Research Center for Infectious Diseases, Institute for Virus Research, Kyoto University, Sakyo-ku, Kyoto \\ 606-8507, Japan; ${ }^{2}$ Center for Animal Resources and Development, Kumamoto University, Kumamoto, Kumamoto 860-0811, \\ Japan; ${ }^{3}$ Center for Medical Genomics, National Cancer Center Research Institute, Chuo, Tokyo 104-0045, Japan; \\ ${ }^{4}$ Laboratory of Systems Biology and Medicine, Research Center for Advanced Science and Technology, The University \\ of Tokyo, Meguro, Tokyo 153-8904, Japan
}

\begin{abstract}
Histone H3 Lys 9 (H3-K9) methylation is a crucial epigenetic mark for transcriptional silencing. G9a is the major mammalian H3-K9 methyltransferase that targets euchromatic regions and is essential for murine embryogenesis. There is a single G9a-related methyltransferase in mammals, called GLP/Eu-HMTase1. Here we show that GLP is also important for H3-K9 methylation of mouse euchromatin. GLP-deficiency led to embryonic lethality, a severe reduction of H3-K9 mono- and dimethylation, the induction of Mage-a gene expression, and HP1 relocalization in embryonic stem cells, all of which were phenotypes of G9a-deficiency. Furthermore, we show that G9a and GLP formed a stoichiometric heteromeric complex in a wide variety of cell types. Biochemical analyses revealed that formation of the G9a/GLP complex was dependent on their enzymatic SET domains. Taken together, our new findings revealed that G9a and GLP cooperatively exert H3-K9 methyltransferase function in vivo, likely through the formation of higher-order heteromeric complexes.
\end{abstract}

[Keywords: Histone; methylation; G9a; GLP]

Supplemental material is available at http://www.genesdev.org.

Received November 29, 2004; revised version accepted February 11, 2005.

In all eukaryotes, genetic information is stored as chromatin, which consists of genomic DNA, histones, and a wide array of chromosomal proteins. The most fundamental unit of chromatin is the nucleosome, which is built from an octamer of core histones, H2A, H2B, H3, and H4, wrapped around $147 \mathrm{bp}$ of DNA (Luger et al. 1997). The N-terminal tails of core histones are subject to a variety of covalent modifications such as phosphorylation, acetylation, methylation, ubiquitination, and ADP-ribosylation. These modifications play critical roles in the nuclear functions of chromatin. The "histone code" hypothesis (Strahl and Allis 2000; Turner 2000; Jenuwein and Allis 2001) predicts that different modifications at specific amino acid residues in histones or combinations of these modifications are translated into functionally distinct nuclear processes. For ex-

${ }^{5}$ Corresponding author.

E-MAIL yshinkai@virus.kyoto-u.ac.jp; FAX 81-75-751-3991.

Article published online ahead of print. Article and publication date are at http://www.genesdev.org/cgi/doi/10.1101/gad.1284005. ample, lysine methylation on histone $\mathrm{H} 3$ or $\mathrm{H} 4$ is involved in a variety of biological processes including transcriptional regulation, DNA elimination, DNA methylation, heterochromatin formation, and X-chromosome inactivation (Lachner and Jenuwein 2002; Lachner et al. 2003; Cao and Zhang 2004a). Distinct effector molecules can read different methyl-lysine codes through specific interactions with the methylated histone. For example, heterochromatin protein 1 (HP1) and Polycomb (Pc) mediate transcriptional repression via their high-affinity interactions with histone H3 methylated at K9 and K27, respectively (Bannister et al. 2001; Lachner et al. 2001; Fischle et al. 2003).

SET domain-containing proteins (SET domain proteins) are potential histone methyltransferases (HMTases), and there are $>50$ putative SET domain protein genes in the mouse genome. Enzymatically characterized SET domain proteins are classified into subgroups by their putative substrate specificities. Among the histone H3 Lys 9 (H3-K9) methyltransferase group genes, at least Suv39h1 (Rea et al. 2000), Suv39h2 (O'Carroll et al. 
2000), G9a (Tachibana et al. 2001), G9a related protein (GLP, also known as EuHMTase1 in human) (Ogawa et al. 2002) and SETDB1/ESET (Schultz et al. 2002; Yang et al. 2002) gene products were demonstrated to catalyze H3-K9 methylation. Mutational studies in mice have shown that each of these H3-K9 HMTases is functionally distinct. For example, ESET was essential for preimplantation development in mice (Dodge et al. 2004), whereas G9a was essential during mid-gestation (Tachibana et al. 2002). Suv39h1 and its homolog, Suv39h2, played redundant but crucial roles after the embryonic day 12.5 (E12.5) developmental stage (Peters et al. 2001). Furthermore, different H3-K9 HMTases target different chromosomal loci and regulate methylation status at the level of mono-, di-, or trimethylation. Suv39h proteins contribute to $\mathrm{H} 3-\mathrm{K} 9$ trimethylation on pericentric heterochromatin, whereas G9a dominantly regulates H3-K9 mono- and dimethylation at euchromatic regions (Peters et al. 2003; Rice et al. 2003).

Methylation of H3-K9 by G9a is an integral component of the transcriptional silencing program for many genes. We have reported that a null G9a-mutation in embryonic stem (ES) cells led to a loss of H3-K9 dimethylation at the Mage- $a$ promoter and reversed transcriptional repression of Mage-a genes (Tachibana et al. 2002). Targeting of G9a and induction of H3-K9 methylation at antigen receptor gene segments suppressed their germline transcription and V(D)|J recombination (Osipovich et al. 2004). Furthermore, G9a-mediated H3-K9 methylation has been implicated in the silencing of developmentally regulated genes via interaction with CDP/cut (Nishio and Walsh 2004), the plasma cell transcription factor Blimp-1 (Gyory et al. 2004), and the neuron-restrictive silencing factor NRSF/REST (Roopra et al. 2004).

Mammals possess only one closely related homolog of G9a, termed GLP/Eu-HMTase1. Recent biochemical studies have shown that several transcriptional silencing complexes, such as E2F6 (Ogawa et al. 2002), CtBP-1 (Shi et al. 2003), and CDP/cut (Nishio and Walsh 2004), contained not only G9a but also Eu-HMTase1. However, genetic studies have shown that mutation of G9a was sufficient to drastically reduce $\mathrm{H} 3-\mathrm{K} 9$ mono- and dimethylation at euchromatic regions. Thus, the in vivo contribution of GLP/Eu-HMTase1 as an H3-K9 HMTase and its functional interaction with G9a remained unknown.

To address these questions, we generated GLP-deficient mice and ES cells. Surprisingly, the phenotypes observed for germline mutations of the G9a and GLP genes were identical in many respects, including embryonic lethality, drastic reduction of $\mathrm{H} 3-\mathrm{K} 9$ mono- and dimethylation, induction of Mage- $a$ genes, and HP1 relocalization in ES cells. These findings indicate that G9a and GLP function cooperatively rather than redundantly to mediate H3-K9 methylation at euchromatin. Moreover, we show that G9a and GLP form a stoichiometric heteromeric complex in vivo, which is likely important for the HMTase function of these proteins during gene repression.

\section{Results \\ Molecular characteristics and expression profiles of GLP}

Figure 1A compares the molecular features of GLP (1296 amino acids) and mouse G9a-S (G9a short form, 1172 amino acids). GLP and G9a exhibit a high overall sequence similarity and a conserved domain structure. The most conserved domain is the SET domain $175 \%$ identities, $87 \%$ positives). The human counterpart of GLP, EuHMTase1, has been shown to express H3-K9 HMTase activity in vitro (Ogawa et al. 2002). To further investigate the substrate specificity and the enzymatic activity of GLP versus G9a, we generated GST-fusion proteins carrying their respective SET domains (amino acids 878-1172 for mG9a-S and 1002-1296 for GLP). The GSTfusion proteins were incubated with S-adenosyl methionine and several recombinant GST-histone H3 tail substrates (amino acids 1-57) (Tachibana et al. 2001). As reported previously, the GST-G9a SET protein preferentially methylated K9 [Fig. 1B, left panel, H3N(K9)] and less efficiently $\mathrm{K} 27$ [H3N(K27)] in our in vitro assay system. The GST-GLP SET protein also methylated K9 preferentially and K27 weakly (Fig. 1B, right panel). Thus, the enzymatic activities of GLP were quite similar to those of G9a.

To explore the biological function(s) of GLP, we examined the intracellular localization profile of GLP as compared with G9a. Newly generated monoclonal antibodies specific for G9a or GLP (epitopes shown in Fig. 1A) were used for detection of the corresponding endogenous proteins using immunohistochemistry. G9a and GLP displayed similar intracellular localization profiles in mouse ES cells and embryonic fibroblasts (Fig. 1C, top and bottom, respectively). Both enzymes were detected exclusively in nuclei, but did not accumulate at DAPIdense heterochromatin, and were excluded from nucleoli.

We also examined RNA expression profiles of $G 9 a$ and GLP by multi-tissue Northern blot hybridization in adult mice (Fig. 1D). G9a and GLP were ubiquitously expressed with some variations at steady-state mRNA levels when comparing different tissues. It was notable that the relative levels of GLP transcripts among the examined tissues were quite proportionate to those of G9a, except in testis, where G9a transcripts were elevated. Collectively, these results suggest that G9a and GLP may possess similar functions as H3-K9 HMTases in vivo.

\section{Generation of GLP-deficient mice and ES cells}

To generate $G L P^{-/-}$mice and cells by genetic mutation, we designed a targeting construct for replacement of exon 25 and a portion of exon 26 with the neomycin gene cassette (Fig. 2A). The replaced sequences encode the catalytic core region of the GLP SET domain (as shown in Fig. 1A, underlined). The targeting construct was introduced into TT2 mouse ES cells (Yagi et al. 1993) and selected by G418/Gnc. From the three hundred clones 


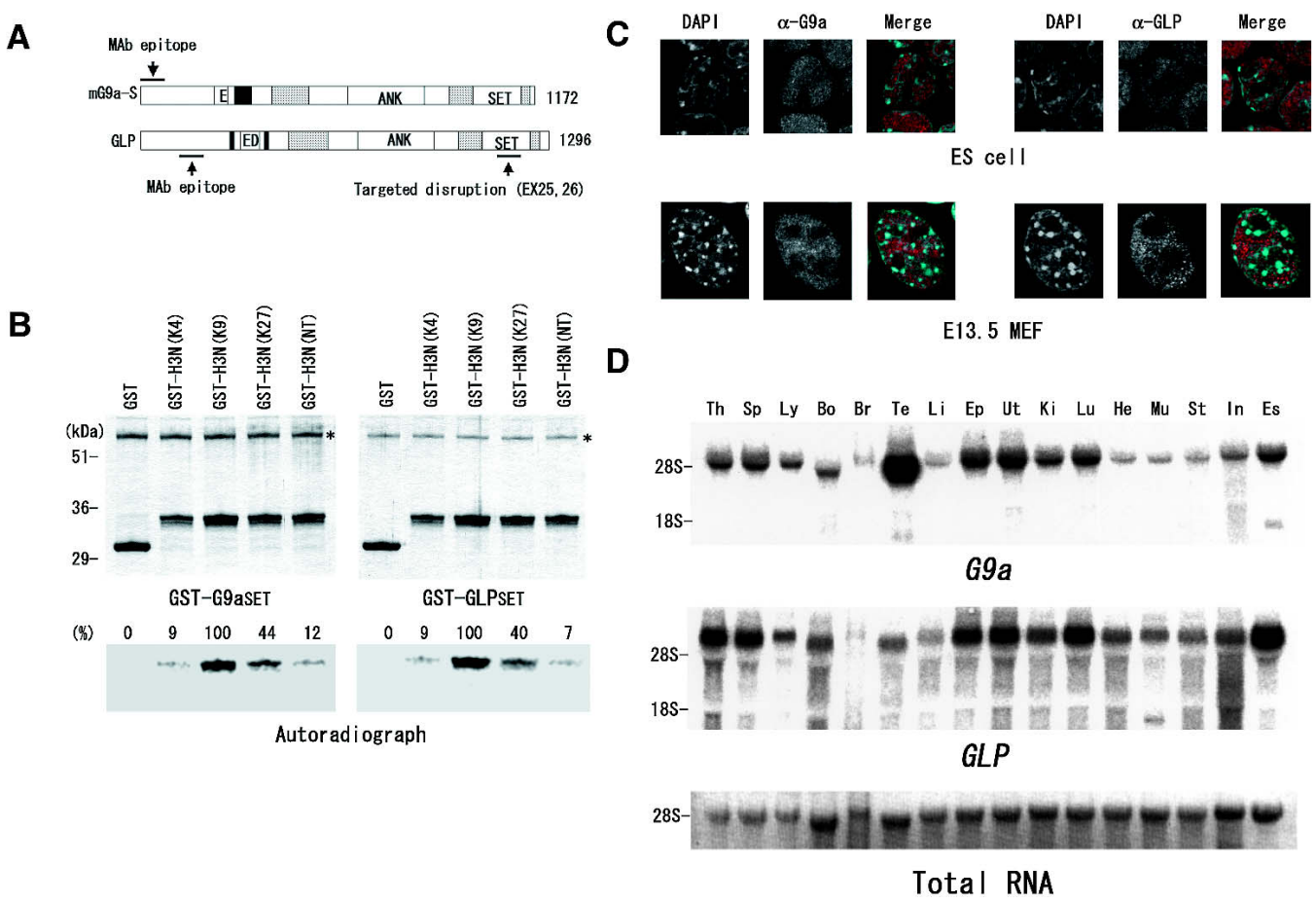

Figure 1. Molecular and expression characteristics of G9a and GLP. (A) Molecular structures of mouse G9a-S and GLP. Black boxes represent putative nuclear localization sequences. Dark boxes represent cysteine-rich regions including pre- and post-SET domains. (ANK) Ankyrin repeats; (SET) SET domains; (E) poly glutamic acid stretch; (ED) acidic region composed of glutamic and aspartic acid repeats. $(B)$ The SET domains of G9a and GLP share the same substrate specificity. HMTase activities of the SET domains of G9a (amino acids 878-1172 for G9a-S, left) and GLP (amino acids 1002-1296, right). The GST-SET domains were incubated with ${ }^{14} \mathrm{C}-$ labeled SAM and several GST-fused H3-N-terminal proteins (1-57) as substrates. Mutant substrates carry double K-to-R substitutions as follows: $4 \mathrm{~K},(9+27) \mathrm{R} ; \mathrm{K} 9, \mathrm{~K}(4+27) \mathrm{R} ; \mathrm{K} 27, \mathrm{~K}(4+9) \mathrm{R}$. (NT) Triple K-to-R substitutions. Asterisks indicate GST-SET domain proteins. $(C)$ Nuclear distributions of G9a and GLP. Wild-type ES cells (top) and mouse primary fibroblasts from wild-type E13.5 embryos (bottom) were stained with DAPI (right, blue) and specific antibodies against G9a or GLP (red). (D) Expression profiles of G9a and GLP transcripts in mouse tissues. Four micrograms of total RNA were probed with radio-labeled G9a (top) and GLP cDNA (middle). (Bottom) 28S ribosomal RNA was visualized by ethidium bromide staining as a loading control. (Th) Thymus; (Sp) spleen; (Ly) lymph node; (Bo) bone marrow; (Br) brain; (Te) testis; (Li) liver; (Ep) epididymis; (Ut) uterus; (Ki) kidney; (Lu) lung; (He) heart; (Mu) skeletal muscle; (St) stomach; (In) intestine; (Es) ES cells (TT2).

screened, we identified eight that carried a correctly targeted GLP allele and no extra copy of the construct. Three clones (\#94, \#138, and \#233) were injected into the morula stage of mouse embryos to generate chimeric animals. Figure $2 \mathrm{~B}$ shows the establishment scheme of $G L P$-deficient ES cells. At first, we introduced a Flagtagged GLP cDNA flanked with two loxP sites into $G L P^{+/-}$ES cells (\#94) and then generated $G L P^{-/-}$ES cells (118) expressing exogenous Flag-tagged GLP molecules. Finally, using Cre-recombinase treatment of 118 cells, we generated GLP-deficient ES cells $(118+)$. In addition, we established three clones of GLP-deficient ES cells (CD10-CD12) by cloning of 118+. The successful generation of $G L P^{-/-}$ES cells was confirmed by both Southern blot (Fig. 2C) and immunoblot (Fig. 2D) analyses. AntiGLP antibody could not detect any truncated polypeptides in $118+$, indicating that our GLP targeting results in a null mutation. Interestingly, GLP-deficiency caused a reduction in the steady-state levels of G9a protein to approximately one-third of those observed in wild-type ES cell, TT2 (Fig. 2D, middle panel, TT2 vs. $118+$ ). RNA hybridization analysis of GLP-deficient ES cells demonstrated no decrease in G9a-transcript levels, indicating that the reduction in G9a protein occurred post-transcriptionally (data not shown).

\section{Embryonic lethality in GLP-deficient mice}

To address the in vivo functions of GLP, we established three lines of $G L P^{+/-}$mice from the \#94, \#138, and \#233 chimeras. The $G L P^{+/-}$offspring were intercrossed and the resultant $G L P^{-/-}$mice (embryos) were subjected to phenotypic analyses. No significant differences were identified between $G L P^{+/+}$and $G L P^{+/-}$mice. However, as shown in Table 1, the heterozygous crosses produced no $G L P^{-/-}$pups from three distinct mouse lines. Thus, we conclude that the $G L P^{-/-}$genotype results in embryonic death. We further examined lethality in the $G L P^{-/-} \mathrm{em}$ bryos using dissection at different developmental stages. At E12.5, embryo proper genotyped as $G L P^{-/-}$could not be detected, and putative $G L P^{-/-}$embryos were already adsorbed completely. Live $G L P^{-/-}$embryo proper could be detected at E9.5, but were reduced from the expected Mendelian ratio. Approximately one-half of the expected 
Tachibana et al.

A

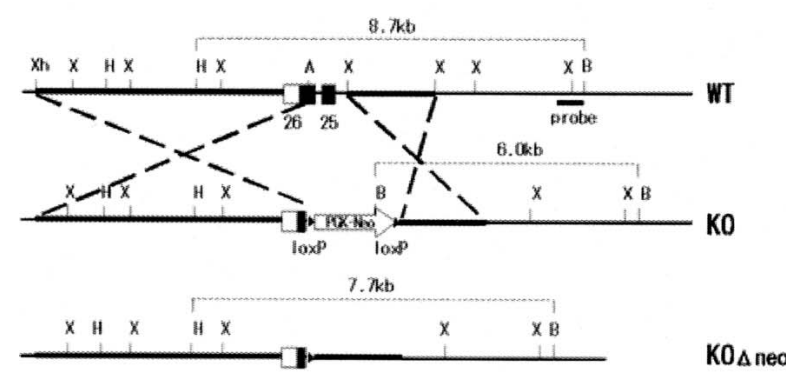

B

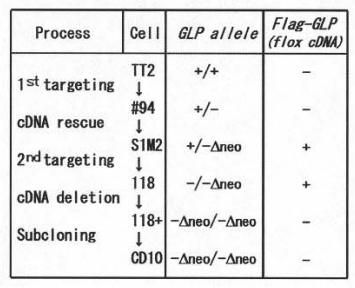

C

TT2 \#94 S1M2 $118 \quad 118+$

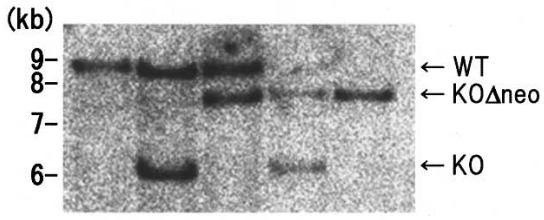

D

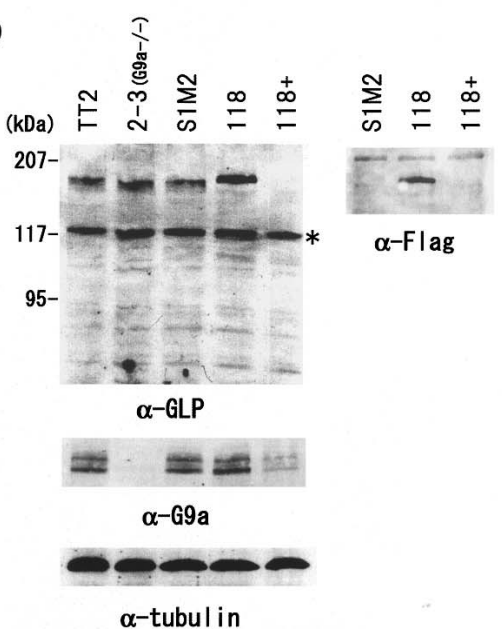

Figure 2. Generation of GLP-deficient mice and ES cells. (A) Partial restriction maps of the mouse GLP locus (exons 25 and 26 , top), and the targeted GLP locus containing a neomycin cassette (middle) are shown. (Bottom) The neomycin cassette can be excised from the targeted locus for disruption of the second allele. The portions of the endogenous locus that were used for constructing the targeting plasmid are shown as thick lines. $(\mathrm{Xh}) \mathrm{XhoI}$; $(\mathrm{H})$ HindIII; (X) XbaI; (A) ArtII; (B) BamHI. (B) Flow diagram for the establishment of GLP-deficient ES cells. To disrupt GLP conditionally with Cre-recombinase, loxP-flanked (flox) Flag-GLP-cDNA was introduced before the second GLP targeting. The 118 cells, which expressed only exogenous Flag-GLP-cDNA, were treated with 5'OHT to excise the Flag-GLP-cDNA. The resultant cells $(118+)$ successfully carried a $G L P$-null genotype. $(C)$ Southern blot analyses of $G L P$ alleles described in $A$. Disruption of the GLP locus was confirmed by Southern blot analysis using BamHI/HindIII-digested DNA probed with a genomic portion located outside of the targeting construct as shown in $A$. $(D)$ GLP deficiency was confirmed by Western blot analyses using total lysates corresponding to $10^{5}$ cells. Endogenous GLP protein was detected at a molecular weight of $\sim 170 \mathrm{kDa}$. (Top) Asterisks represent nonspecific signals detected by the secondary antibodies. (Bottom) Tubulin contents were also determined as a loading control.

$G L P^{-/-}$embryos were dead at E9.5. Some of these embryos were completely adsorbed and the remainder consisted only of a residual yolk sac, suggesting that $G L P^{-/-}$ embryos die around E9.5. Notably, viable GLP $P^{-/-}$embryos at E9.5 could be distinguished from $G L P^{+/+}$and $G L P^{+/-}$littermates by their morphological properties, because they exhibited severe growth retardation. The gross morphology of typical E9.5 GLP $P^{-/-}$embryos is shown in Figure 3A (left). The cell mass of these GLP $P^{-/-}$ embryos was estimated at approximately one-fifteenth that of wild type (data not shown). The E9.5 GLP ${ }^{-/-}$embryos developed only to the 4-6 somite stage (Fig. 3A, upper left) as opposed to the $21-25$ somite stage in wildtype siblings. In addition, the neural groove of $G L P^{-/-}$ embryos was closed only at the tail region but not at the anterior region. These morphological characteristics of the E9.5 GLP $\mathrm{GP}^{-/-}$embryos resembled those of the E8.0E8.5 wild-type embryos, and no organ-specific abnormalities were recognized. Most importantly, levels of
H3-K9 dimethylation in $G L P^{-/-}$embryos were drastically reduced when compared with those observed for wild-type embryos (Fig. 3B). The latter data demonstrate that GLP is also a critical H3-K9 HMTase in vivo. In conclusion, the phenotypes of $G L P^{-/-}$embryos were mostly identical to those of $G 9 a^{-/-}$embryos (Tachibana et al. 2002), suggesting that G9a and GLP coordinate common functions during embryonic development.

Drastic reduction of mono- and dimethylated H3-K9 and relocalization of HP1 proteins in $\mathrm{GLP}^{-/-}$ES cells

To clarify the impact of GLP deficiency on H3-K9 methylation, we compared the levels of this histone modification among wild-type (TT2), $G 9 a^{-/-}(2-3)$, and $G L P^{-/-}$ (CD10) ES cells (Fig. 4A,B). As reported previously (Peters et al. 2003; Rice et al. 2003), Western blot analysis clearly showed that H3-K9 mono- and dimethylation was severely diminished in the $G 9 a^{-/-}$ES cells (Fig. 4A). 
Table 1. Embryonic lethality of GLP-deficient mice

\begin{tabular}{lcccc}
\hline & \multicolumn{3}{c}{ Genotype } & \\
\cline { 2 - 4 } & $+/+$ & $+/-$ & $-/-$ & Complete resorption \\
\hline Newborn & & & & \\
$\quad$ \#4 & 18 & 18 & 0 & - \\
$\# 138$ & 10 & 26 & 0 & - \\
$\# 233$ & 17 & 38 & 0 & - \\
Embryo & & & & 9 \\
E12.5 & 8 & 17 & $2^{\mathrm{a}}$ & 3 \\
E10.5 & 5 & 9 & $3\left(1^{\mathrm{b}}+2^{\mathrm{a}}\right)$ & 4 \\
E9.5 & 12 & $23\left(1^{\mathrm{b}}\right)$ & $8\left(6^{\mathrm{b}}+2^{\mathrm{a}}\right)$ & \\
\hline
\end{tabular}

${ }^{a}$ No embryo proper and only yolk sack remained.

${ }^{\mathrm{b}}$ Severely growth-retarded embryo proper.

The $G L P^{-/-}$ES cells also exhibited a drastic reduction in mono- and dimethylated H3-K9 but no alteration in H3K9 trimethylation. Due to our previous data for H3-K9 dimethylation in $69 a^{-/-}$ES cells (Tachibana et al. 2002), we estimated that the reduction of $\mathrm{H} 3-\mathrm{K} 9$ dimethylation in $G L P^{-/-}$ES cells was also approximately one-eighth. Immunostaining analysis confirmed the specific disappearance of mono- and dimethylated H3-K9 signals in $G 9 a^{-/-}$and $G L P^{-/-}$ES cells, which were detected mostly at euchromatic regions in wild-type nuclei (Fig. 4B). These data further indicate that G9a and GLP are equally required for overall H3-K9 mono- and dimethylation in vivo.

The enrichment of HP1 proteins at pericentric heterochromatin is strictly dependent on $\mathrm{H} 3-\mathrm{K} 9$ methylation by Suv39h family HMTases (Lachner et al. 2001). However, the HP1 proteins also localize to euchromatic loci (Eissenberg and Elgin 2000). Thus, we examined whether deletion of GLP or G9a affects the nuclear localization of $\mathrm{HP} 1$ proteins (HP1 $\alpha, \mathrm{HP} 1 \beta$, and $\mathrm{HP} 1 \gamma)$. In wild-type ES cells, dense signals for $\mathrm{HP} 1 \alpha$ and $\mathrm{HP} 1 \beta$ were detected on pericentric heterochromatin, whereas $\mathrm{HP} 1 \gamma$ was widely dispersed on euchromatin (Fig. 4C; Eissenberg and Elgin 2000). Significant amounts of $H P 1 \alpha$ and $H P 1 \beta$ signals were also detected in the euchromatic regions. In contrast, both $G 9 a^{-/-}$and $G L P^{-/-}$ES cells showed distinct HP1 nuclear localization profiles. All of the HP1 proteins accumulated into pericentric heterochromatin regions and were significantly reduced at euchromatic regions (Fig. 4C, 2-3 and CD10 panels). Total amounts of HP1 proteins were unaltered among these ES cells (data not shown). Thus, G9a- and GLP-mediated methylation of H3-K9 affects the subnuclear distribution of HP1 to euchromatin.

\section{H3-K9 hypomethylation induces Mage-a gene expression in $\mathrm{GLP}^{-/}$ES cells}

Next, we examined the expression of Mage-a family genes in $G L P^{-/-}$ES cells, since the expression of certain Mage- $a$ genes was induced in G9a-deficient ES cells (Tachibana et al. 2002). As shown in Figure 4D (left panel), Mage- $a$ gene(s) expression was also induced in all three $G L P^{-/-}$ES cell lines examined (CD10-CD12) but was undetectable in wild-type TT2 cells and GLP cDNA positive S1M2 cells. We have also reported that G9a deficiency caused a significant decrease in H3-K9 dimethylation and an increase in $\mathrm{H} 3-\mathrm{K} 4$ dimethylation on the Mage-a2 promoter region in ES cells (Fig. 4D, right panel; Tachibana et al. 2002). Accordingly, we analyzed the methylation status of $\mathrm{H} 3$ on the Mage-a2 promoter region in $G L P^{-/-}$ES cells. Chromatin immunoprecipitation analysis clearly demonstrated that H3-K9 dimethylation was reduced and $\mathrm{H} 3-\mathrm{K} 4$ dimethylation was increased on the Mage-a2 promoter region in the GLPdeficient cells (Fig. 4D, right panel). This result provides further support to our model that GLP functionally overlaps with G9a, not only on a chromosome-wide level but also for a specific genetic locus.

Finally, we complemented the $G L P^{-/-}$ES cells with a cDNA encoding the wild-type protein. As shown in Figure 4E, all phenotypes observed for the GLP deficiency, including G9a protein instability (left middle panel), loss of H3-K9 dimethylation (center middle panel), and derepression of Mage-a transcripts (right upper panel), were rescued, indicating that the observed $G L P^{-/-}$phenotypes were intrinsic.

\section{G9a and GLP exist as heteromeric complexes in vivo}

Our data not only demonstrate that G9a and GLP exhibit significant functional overlap, but also that G9a protein stability is at least partially dependent on GLP. One potential explanation for these results is that the two HMTases function as components of a higher-order complex. Indeed, a subset of transcriptional suppressive complexes in human cells contained both G9a and EuHMTase1 (Ogawa et al. 2002; Shi et al. 2003; Nishio and
A

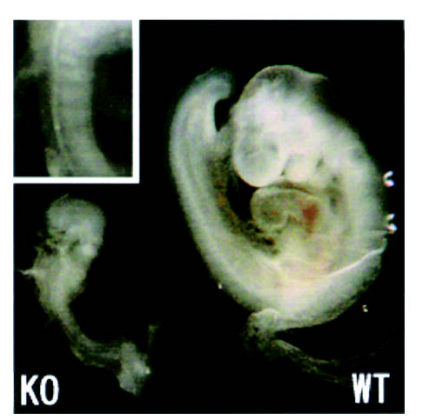

B

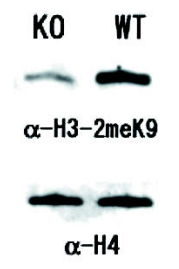

Figure 3. GLP-deficiency results in embryonic-lethality. $(A)$ The gross morphology of a typical GLP-deficient embryo (left) and a wild-type sibling (right) at E9.5. GLP-deficient embryos were severely growth-retarded, containing only 4-6 somites (enlarged in upper left), while wild-type siblings had 21-25 somites. (B) Acid-extracted histones from E9.5 whole embryos were separated by SDS-PAGE and followed by immunoblotting with antidimethyl H3-K9 (top) or anti-H4 antibodies (bottom). The levels of H3-K9 dimethylation were drastically reduced in GLP-deficient whole embryos. 
Walsh 2004). As such, we examined the association of endogenous G9a and GLP by coimmunoprecipitation assays (Fig. 5A). In wild-type TT2 cells, both G9a and GLP coprecipitated efficiently with antibodies specific for either G9a or GLP (Fig. 5A, lanes 4,7). Control immunoprecipitations confirmed the specificity of this interaction. GLP failed to precipitate with anti-G9a antibodies from $G 9 a^{-/-}$ES cell extracts. Likewise, G9a was not detected in anti-GLP precipitates from $G L P^{-/-}$ES cells (Fig. $5 \mathrm{~A}$, lanes 5,91 . The G9a/GLP interaction was stable under highly stringent conditions using the detergent buffer RIPA (Fig. 5A), or even in high salt (0.5 M) conditions (data not shown).

To determine the stoichiometry of G9a/GLP complexes, we first purified each recombinant protein from insect cells infected with baculovirus vectors encoding mouse G9a-S or GLP (Fig. 5B, left panel). These recombinant proteins were used as standards to compare G9a and GLP concentrations in immunocomplexes. Immunoprecipitates with anti-G9a or anti-GLP Abs were prepared from wild-type ES cells and subjected to immunoblot analysis using the same antibodies (Fig. 5B, right panel). Western blot analysis with the recombinant standards showed that both anti-G9a and anti-GLP immunoprecipitates contained nearly equal amounts of each HMTase. Next, we carried out sequential immunodepletion analysis with anti-G9a and GLP antibodies using the wild-type ES cell extract (Fig. 5C). Two consecutive immunoprecipitations with anti-G9a resulted in an efficient depletion of both G9a and GLP from the cell extracts. The ratio of G9a/GLP signal intensities was main-

Figure 4. Phenotypes of GLP-deficient ES cells. $(A, B)$ The H3K9 methylation status of TT2 (wild type), G9a-deficient (2-3), and GLP-deficient cells (CD10) was analyzed by Western blot $(A)$ and immunostaining analyses $(B)$. $(A$, left $)$ GLP protein was absent from in CD10 cells. The reduction in levels of H3-K9 mono-and dimethylation in GLP-deficient cells were indistinguishable from that observed in 2-3 cells. Overall H3-K9 trimethylation at pericentric heterochromatin was unaffected in the mutant cells. (C) The G9a or GLP mutations alter the nuclear distribution of HP1 proteins. Mutant cell nuclei were stained with specific antibodies against three HP1 isoforms $(\alpha$, left; $\beta$, middle; $\gamma$, right panels). In G9a- and GLP-mutant cells, euchromatic staining profiles of HP1 had significantly disappeared, but were enriched at pericentic loci. $(D)$ GLP suppressed Mage- $a$ gene expression. (Left) Five micrograms of total RNA were separated and probed with radiolabeled Mage- $a$ cDNA. Fixed and sonicated chromatin of TT2, 2-3, and CD10 ES cells were immunoprecipitated with the indicated Abs and applied to the semiquantitative assay. (Right) H3-K9 dimethylation was reduced and H3-K4 dimethylation was increased on the Magea2 promoter region in G9a- and GLP-deficient cells. (E) GLPcDNA introduction can rescue GLP-deficient phenotypes. A $G L P$-cDNA driven by the chicken $\beta$ actin promoter was introduced stably into GLP-deficient cells. (Left panels) In rescued clones L2 and L6, which expressed GLP at levels comparable to those observed in wild-type cells, the protein stability of G9a was recovered. Similarly, dimethyl H3-K9 levels and Mage-a gene suppression were restored (middle and right panels, respectively). tained in the second-round immunocomplexes (Fig. 5C, left panel). Anti-GLP immunodepletion produced identical results (Fig. 5C, right panel). These data revealed two novel features of the G9a/GLP complex in wild-type ES cells. First, the G9a/GLP complex is the predominant form of these HMTases. Second, the molecular stoichiometry of this complex is nearly one to one, suggesting that G9a and GLP function in vivo as either a heterodimer or as a multimer composed of equal amount of two enzymes.

To rule out the possibility that heteromeric complex formation between G9a and GLP is restricted to ES cells, we analyzed an additional panel of mouse cells. Nuclear

A

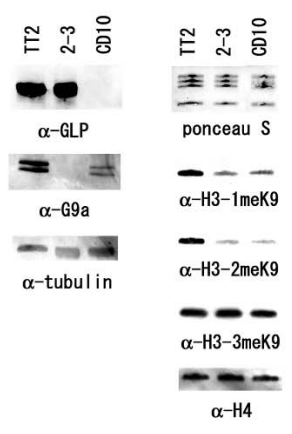

B
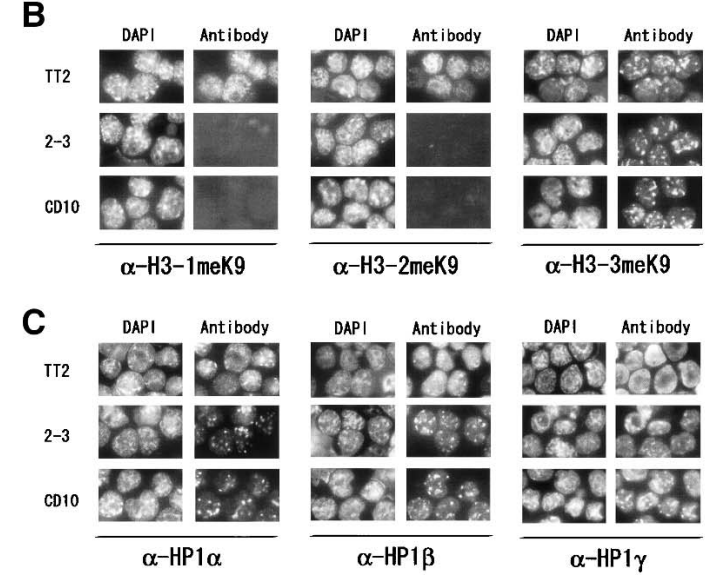

D
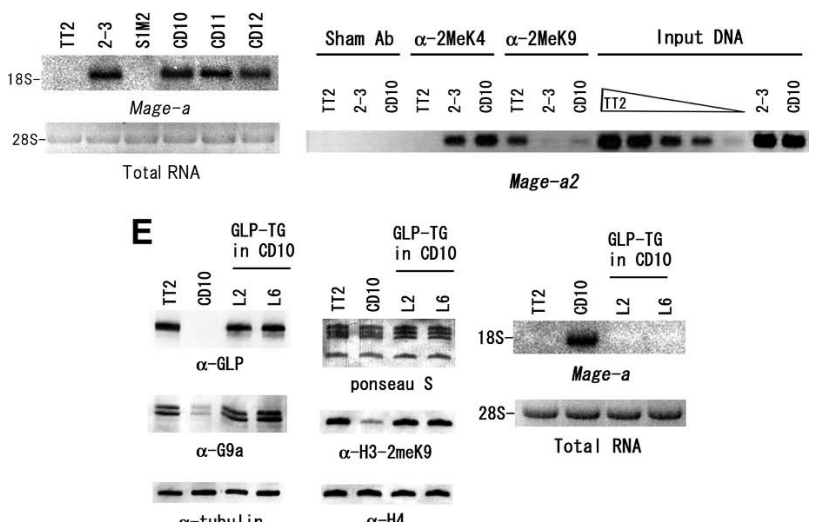

Mage-a2

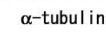

$\alpha-\mathrm{H} 4$ 

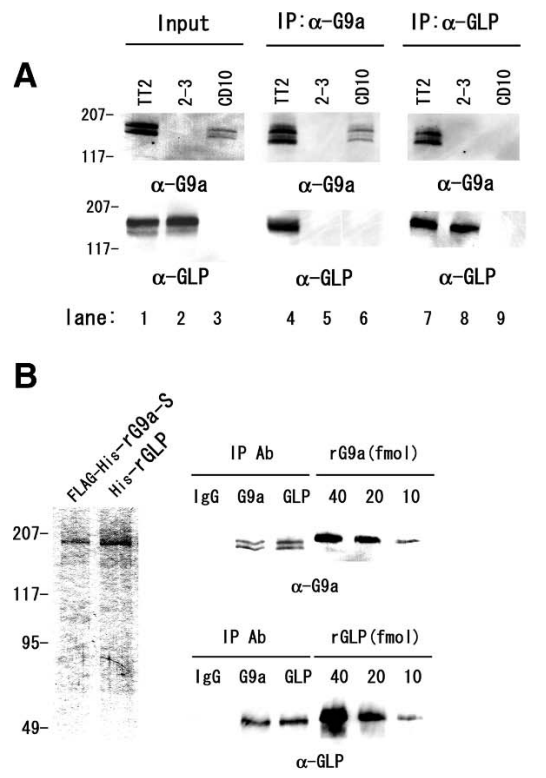

C

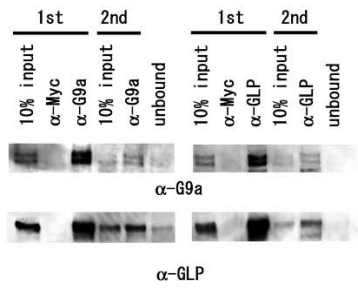

D
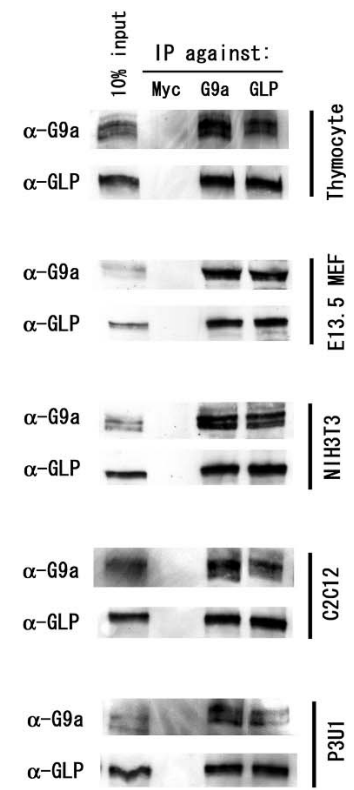

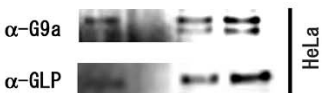

Figure 5. G9a and GLP form heteromeric complexes. (A) Endogenous G9a and GLP were coprecipitated with specific antibodies against G9a or GLP. (Middle panels) Only the anti-G9a immunocomplexes from wild-type nuclear extracts contain GLP. (Right panels) Similarly, immune complexes from wild-type cells obtained with anti-GLP antibody also contain G9a. (B) Quantitative analyses of anti-G9a and anti-GLP immunocomplexes. (Left) Semipurified recombinant G9a and GLP from virus-infected insect cells were used as protein standards. Amounts of G9a or GLP protein content in immunocomplexes from wild-type nuclear extracts were measured by immunoblotting with precalibrated recombinant G9a or GLP. (Right) Each of the anti-G9a or antiGLP immunocomplex contains between 10 and $20 \mathrm{fmol}$ of each molecule. $(C)$ G9a/GLP predominantly form heteromeric complexes. Two sequential immunodepletions using anti-G9a (left) or anti-GLP (right) led to a drastic reduction of both proteins from nuclear extracts. (D) G9a and GLP ubiquitously form a heteromeric complex. Anti-G9a and anti-GLP immunocomplexes were prepared from mouse adult thymocytes, E13.5 primary fibroblasts, the NIH3T3 cell line, the $\mathrm{C} 2 \mathrm{C} 12$ myocyte cell line, the myeloma cell line P3U1, and the human cell line HeLa and were subjected to Western blot analysis. G9a and GLP formed a heteromeric complex in all murine and human cells tested and this heteromeric complexes were the predominant form.

lysates from adult thymocytes, E13.5 primary fibroblasts, the NIH3T3 cell line, the $\mathrm{C} 2 \mathrm{C} 12$ myocyte cell line, and the myeloma cell line P3U1 were subjected to coimmunoprecipitation studies. As shown in Figure 5D, the G9a/GLP heteromeric complex was clearly detected in all cell types examined. The signal ratios of G9a/GLP in most immunocomplexes were strikingly similar to those observed for wild-type ES cells. Moreover, G9a/ GLP heteromers were readily detected in the human cell lines HeLa and HEK293T (Fig. 5D; data not shown). These data strongly suggest that the association of G9a and GLP to form heteromeric complexes is highly conserved in mammalian cells.

\section{Formation of G9a/GLP heteromeric complexes requires their SET domains}

Next, we analyzed the specificity of the interactions between G9a and GLP. For this purpose, we coexpressed EGFP-tagged H3-K9 HMTases (Suv39h1, ESET, or GLP) with Flag-tagged G9a-S in HEK 293 T cells (Fig. 6A). FlagG9a-S coprecipitated EGFP-GLP but not EGFP-Suv39h1 or EGFP-ESET (Fig. 6A, lane 3). An identical approach was applied to test interactions between EGFP-tagged Suv39h1, ESET, or G9a and Flag-tagged GLP (Fig. 6B). Again, Flag-GLP only coprecipitated EGFP-G9a but not other H3-K9 HMTases. However, interactions between Flag-G9a-S or Flag-GLP and their partner molecules lacking their $\mathrm{C}$-terminal catalytic domains were drastically reduced (Fig. 6A,B, EGFP-GLP $\Delta$ SET and EGFP-G9a $\Delta$ SET lanes). These findings strongly suggest that the SET domains of G9a and GLP are essential not only for their enzymatic activities but also for heterodimerization. Finally, we examined whether G9a and GLP can form complexes directly. To test this possibility, Sf9 insect cells were coinfected with baculoviruses encoding G9a and GLP. After $2 \mathrm{~d}$ in culture, nuclear extracts from the coinfected Sf9 cells were prepared and subjected to immunoprecipitation analysis using anti-G9a or anti-GLP Abs. As shown in Figure 6C (lanes 3,4), recombinant G9a and GLP clearly formed heteromeric complexes even when they were produced in the insect cells. However, if we prepared recombinant G9a and GLP independently from the insect cells and then assayed for G9a/GLP complex formation in the mixture, we could not detect the G9a/GLP association (Fig. 6C, lanes 7,8).

One potential explanation for the latter finding is that G9a and GLP can form not only heterodimers but also homodimers and the independently expressed G9a and GLP immediately formed stable homodimers via their SET domains. If correct, further G9a/GLP heterodimer formation could not occur efficiently in this mixing experiment. To address this possibility, we produced Flag- 
Tachibana et al.

Figure 6. G9a/GLP heteromeric complexes require their SET domains. $(A, B)$ Specificity and interaction domain analysis for the G9a and GLP proteins. Flag-G9a-S $(A)$ and GLP $(B)$ were coexpressed with several other EGFP-tagged, H3-K9 HMTases specified at the top of the figure. Immunoprecipitates were collected with control anti-Myc antibody or anti-Flag antibody. Neither G9a nor GLP interacted with Suv39h1 or ESET. Deletion analysis indicated that the interaction between G9a and GLP required their SET domains. (C) Interaction of recombinant G9a and GLP in insect cells. Vaculo viruses encoding G9a or GLP were coinfected (left) or independently infected (right) to Sf9 cells, and recombinant G9a and GLP were collected with anti-G9a or antiGLP antibodies. G9a and GLP could interact in insect cells when the corresponding viruses were coinfected (left panels), whereas the mixture of lysate from independently infected cells could not produce a G9a/GLP heterotypic interaction. (D) G9a and GLP can interact homotypically. Flag-G9a-S (left) or Flag-GLP (right) were coexpressed with their EGFP-tagged versions, and collected with control anti-Myc antibody or antiFlag antibody. Homomeric interaction of G9a or GLP was also dependent on their SET domains. $(E, F)$ SET domains are necessary and sufficient for dimerization. (E) Generation of epitopetagged SET domains. G9a-SET (amino acids 8781172 for G9a-S) and that of GLP (amino acids 1002-1296) carrying Myc- or Flag-tag were expressed in HEK 293 T cells and detcted with antitag antibodies. $(F)$ Interaction between the SET domains. Combinations of SET domain proteins indicated at top were coexpressed in HEK 293T cells and subjected to immunocomplex analyses using control IgG1 or anti-Flag antibody. (Top) Immunoblot analysis with anti-Myc indicated that the SET domains can hetero- or homodimerize. For negative control, Myc-G9a-SET and FlagEGFP proteins were coexpressed and subjected to immunocomplex analyses. (Bottom) Neither anti-Myc nor anti-Flag immunoprecipitates contained partner molecule. Asterisk indicates protein-G signals extracted from resin.
A

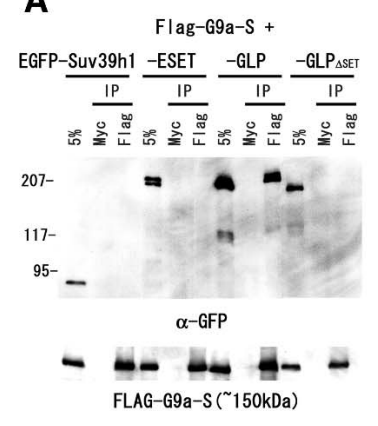

B

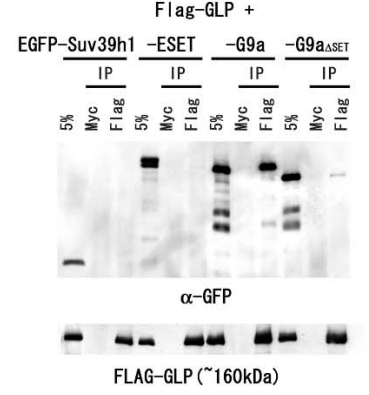

C

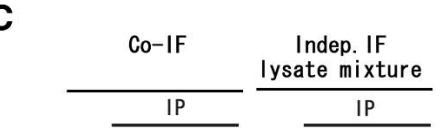

D

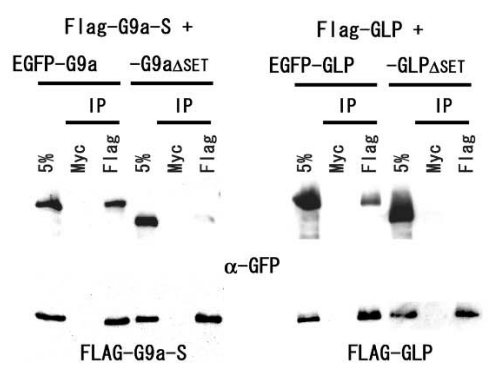

E

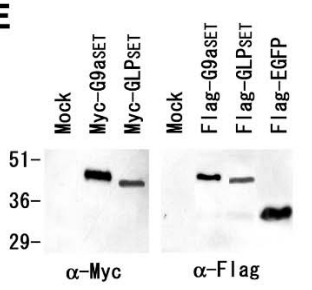

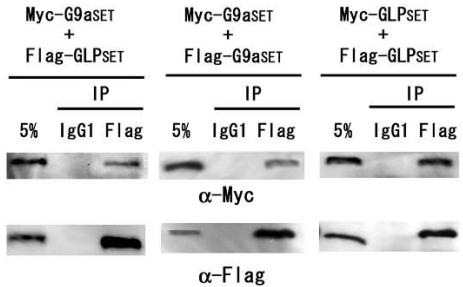

Myc-G9aSET +

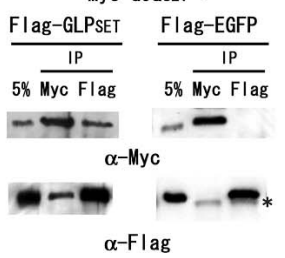

tagged G9a or GLP and EGFP-tagged G9a, GLP, or their SET domain-deletion mutants in HEK 293T cells. As shown in Figure 6D, both G9a and GLP clearly formed homomeric complexes in a SET domain-dependent fashion. To further evaluate the dependence of complex formation on G9a- and GLP-SET domains, we constructed two different epitope-tagged versions of each SET domain and introduced these expression plasmids into HEK 293T cells (Fig. 6E). As shown in Figure 6F, all combinations of the SET domains interacted as complexes. Specifically, Myc-tagged SET domains were coimmunoprecipitated by anti-Flag antibody but not by control antibody (Fig. 6F, upper panel). As a specificity control, we showed that Flag-tagged EGFP did not associate with Myc-tagged SET domains in this assay (Fig. 6F, lower panel; data not shown). Together, these biochemical data strongly suggest that the SET domains of G9a and GLP are necessary and sufficient to mediate hetero- or homomeric interactions.

\section{Discussion}

\section{G9a and GLP form functional dimeric complexes} in vivo

Our biochemical studies clearly revealed that G9a and GLP form homo- and heteromeric complexes dependent on their SET domains. However, G9a and GLP preferentially form heteromeric complexes when cells express both of these HMTases (Fig. 5B,C). In this regard, we found that steady-state levels of G9a decreased in cells lacking GLP (Figs. 2D, 4E). These data suggest that G9a 
is more stable in the G9a/GLP heteromeric complex than when it is expressed alone. However, the converse apparently does not apply to GLP since GLP content was unaffected in $G 9 a^{-/-}$ES cells. Recent reports indicate that some transcriptional silencing complexes from human cell lines, such as E2F6 (Ogawa et al. 2002), CtBP1 (Shi et al. 2003), and CDB/cut (Nishio and Walsh 2004), contained not only G9a but also Eu-HMTase1. Our new data demonstrate that G9a/GLP heteromeric complexes are the predominant form of these proteins in most of the mouse cells examined (Fig. 5D; data not shown). Together, these findings support our working hypothesis that G9a and Eu-HMTase1/GLP form heteromeric complexes that function as the in vivo H3-K9 HMTase. Interestingly, two other SET domain HMTases have been reported to form dimers. vSET from Paramecium bursaria chlorella virus, which can dimethylate H3-K27, forms dimers via a Domain II-Domain II interaction between SET domains (Manzur et al. 2003). The Drosophila Suv39h homolog dSU(VAR)3-9 was also shown to form dimers via its $\mathrm{N}$ terminus (Eskeland et al. 2004). It is possible that more SET domain proteins form dimers to exert HMTase activity in vivo.

\section{Regulation of global HP1 targeting}

by G9a/GLP-mediated H3-K9 methylation

Loss of H3-K9 mono-and dimethylation by mutation of G9a or GLP resulted in a gross relocalization of HP1 (Fig. 4C). In null cells, all HP1 proteins accumulated at pericentromeric heterochromatin without a corresponding induction of H3-K9 trimethylation (Fig. 4B). These data strongly suggest that G9a/GLP-mediated methylation of H3-K9 methylation also directs the global recruitment of HP1 proteins to euchromatin. HP1 binding to "heterochromatin domains" is not static but highly dynamic (Cheutin et al. 2003; Festenstein et al. 2003). HP1 isoforms interact with the $\mathrm{H} 3 \mathrm{~N}$ terminus peptides containing di- and trimethylated $\mathrm{H} 3-\mathrm{K} 9$ with similar binding constants in vitro (Fischle et al. 2003). Therefore, the balance of Suv39h- and G9a/GLP-mediated H3-K9 methylation is one of the critical factors for HP1 dynamics and its binding to specific chromatin domains. However, in general, HP $1 \alpha$ and HP $1 \beta$ seem to be more abundant at pericentromeric heterochromatin where the density of H3-K9 trimethylation is relatively high. HP1 also interacts with Suv39h and Suv4-20h HMTases, both of which localize to pericentromeric heterochromatin (Aagaard et al. 1999; Schotta et al. 2004). These factors in combination probably enhance the retention of HP1 $\alpha$ and HP1 $\beta$ to pericentromeric heterochromatin.

\section{G9a and GLP cooperatively exert H3-K9 methyltransferase function in vivo}

The current studies show that G9a and GLP are equally critical for euchromatic H3-K9 mono- and dimethylation and do not function redundantly in this regard. In support of this conclusion, we have also established G9a/
GLP doubly-deficient ES cells, but observed no additional defects in H3-K9 methylation when compared with G9a or GLP single-deficient ES cells (data not shown). In conjunction with biochemical studies (see below), our data imply that heteromeric complexes containing G9a and GLP are essential for H3-K9 methylation at euchromatin. Thus, G9a/GLP-mediated catalysis is quite different from that observed for other H3-K9 HMTases in vivo. Mice harboring single mutations in either Suv39h1 or its homolog Suv39h2 exhibit no apparent phenotype. Loss of $\mathrm{H} 3-\mathrm{K} 9$ trimethylation and chromosomal instability are observed only when both of these genes are mutated (Peters et al. 2001). These findings indicate that, unlike G9/GLP, the Suv39h proteins function redundantly in vivo even if they form dimeric complexes.

Mammalian HMTases have been divided into two categories based on their in vitro substrate preferences. One type of enzymes preferentially methylates histones in a nucleosomal context. This category includes the H3-K27 HMTase EZH2 (EED-EZH2 complex) (Cao and Zhang 2004b), and the H4-K20 HMTases pr-SET7 (Fang et al. 2002; Nishioka et al. 2002) and Suv4-20h1,h2 (Schotta et al. 2004). The other type of HMTases methylates histone octamers, but exhibit a low rate of catalysis for nucleosomal histones. Interestingly, all of the characterized H3-K9 HMTases in mammals (i.e., Suv39h, EuHMTase1/GLP, and SETDB1/ESET), belong to the latter group (Ogawa et al. 2002; Wang et al. 2003; Schotta et al. 2004). To assess whether any enzymatic differences existed between the G9/GLP heteromeric complex and G9a or GLP alone, we performed in vitro HMTase assay (Supplementary Fig. S1; data not shown). We found no difference in enzymatic activities for the heteromeric complex, each molecule alone or the mixture of two enzymes, and all forms only methylated naked histone $\mathrm{H} 3$ but not $\mathrm{H} 3$ in nucleosomes. Thus, these in vitro data add further support to the notion that H3-K9 HMTases are the naked-histone preferring methyltransferase, but they could not demonstrate the functional role of the G9a/ GLP complex formation on their euchromatic H3-K9 methylation nor functional relationship of the two enzymes.

Recently, it was reported that the H3-K9 HMTase, termed SETDB1, forms a higher-order complex with the methyl-CpG-binding protein MBD1 and the chromatin assembly factor CAF-1 in an S-phase specific manner. This finding implies that SETDB1 may exert HMTase activities when coupled with DNA replication (Sarraf and Stancheva 2004). In this context, it is possible that $\mathrm{H} 3-\mathrm{K} 9$ methylation is tightly regulated in the cell cycle and mostly targeted to the newly synthesized $\mathrm{H} 3$ when deposited into nucleosomes during replication. If this hypothesis is correct, we speculate that G9a/GLP heteromeric complex formation might have a key role in their euchromatic H3-K9 mono- and dimethylation in the specific timing of the chromatin dynamics in vivo.

Further studies are necessary to dissect the specific biological roles of G9a/GLP heteromeric complexes in vivo. It certainly remains possible that G9a or GLP have 
a unique function in specific cell types such as murine testicular cells where the $G 9 a$ gene is predominantly expressed. Finally, it will be of great interest to determine the physiological relevance of the G9a/GLP dual-enzyme regulation on euchromatic $\mathrm{H} 3-\mathrm{K} 9$ methylation.

\section{Materials and methods}

Generation and genotyping of the GLP-mutant embryos and ES cells

A mouse GLP cDNA fragment corresponding to amino acids 1002 to its termination was used as a probe to screen a TT2 genomic library. To make a GLP targeting construct, a $6.0-\mathrm{kb}$ genomic fragment, spanning from the AatII site in exon 26 to the XhoI site downstream of exon 26, was inserted into the modified SalI site of two loxP-contaning plasmid, pLNTK, and then a $1.8-\mathrm{kb}$ XbaI genomic fragment located in the intron between exon 24 and 25 was further subcloned into the XhoI site. The GLP targeting construct replaces exon 25 and a portion of exon 26 of mouse GLP gene with the pgk-neomycin gene.

TT2 ES cells $\left(1 \times 10^{7}\right)$ were transfected with $20 \mu \mathrm{g}$ of the XhoIlinearized GLP-targeting construct and screened as described previously (Tachibana et al. 2002). Homologous recombinant clones (\#94, \#138, and \#233) were identified by Southern blot analysis of BamHI/HindIII digested DNA probed with a PCRamplified genomic fragment located between exons 24 and 25 . Southern blot analysis with a fragment of neomycin gene confirmed that there were no extra copies of the targeting construct integrated randomly into the genome of the recombinant cells. The recombinant cells were injected into the morula stage of ICR mouse embryos. Established chimeric male mice derived from the three clones described above successfully generated $F_{1}$ offspring carrying the mutated GLP allele.

To establish GLP-/- ES cells, pCAGGS-Mer-Cre-Mer and pCAGGS-loxP-flanked (flox) Flag-GLP cDNA expressing plasmids were stably introduced into $G L P^{+/-\Delta \text { neo }}$ ES cells, which had been generated by removal of the pgk-neomycin cassette from $G L P$-targeted allele with transient Cre recombinase treatment. The intact allele in $G L P^{+/-\Delta \text { neo }}$, flox Flag-GLP+ ES cells was further targeted with the $G L P$-targeting construct to generate $G L P^{-/- \text {sneo }}$, flox Flag-GLP $P^{+}$ES cells. Finally, Flag-GLP cDNA was excised from the genome by $2 \mathrm{~d}$ culture with 4-hydroxytamoxytamoxyfen (OHT). After OHT treatment, three cell lines (termed CD10, CD11, and CD12) carrying $G L P^{-\Delta \text { neo/- } \Delta \text { neo }}$ alleles were obtained by subcloning. PCR detection of the $G L P$-mutant allele was carried out using primers external to the short arms of the targeting construct $\left(\mathrm{G} 3,5^{\prime}\right.$-GG GCCAGCTCATTCCTCCACTC-3' and GLP2nd-40F, 5'-GA TCAAATCAGGTTAGGTTCAGTGCCAG-3'). 7021R (5'-GT GGGCAGTCTCATGTCTGCCTGCGGAC-3'), and 6180F (5'CTCAGGTGAGATAACTCAAGTACCCCTAAG-3') primers within the intron between exons 26 and 25 were used for detection of intact GLP allele.

\section{Antibodies}

For detection of G9a, hamster monoclonal antibody \#14-1 (MBL) or mouse monoclonal antibody \#8620 was used. For detection of GLP, hamster monoclonal antibody C7-5 or mouse monoclonal antibody \#422 was used. Anti-G9a \#8620 was generated to recognize an epitope embedded within amino acid positions from 15 to 114 of the G9a-S polypeptide, the sequences of which were also conserved in G9a-L. Anti-GLP \#422 was generated to recognize an epitope embedded within amino acid positions from 1 to 81 of the GLP polypeptide. These two monoclonal antibodies were raised by immunizing mice with recombinant baculovirus particles displaying amino acid sequences of G9a or GLP shown above as fusion proteins to the viral surface glycoprotein gp64 as previously described (Tanaka et al. 2002). For detection of epitope tagged-protein, rabbit antiGFP (MBL) and anti-Flag M5 (Sigma) were used. The methylation status of H3-K9 was analyzed with anti-monomethyl H3K9 (Upstate, \#07-395), anti-dimethyl H3-K9 (\#07-212), and antitrimethyl H3-K9 (\#07-523) antibodies. To control for protein loading, anti-histone $\mathrm{H} 4$ (Upstate, \#07-108), anti-tubulin (Oncogene, CP06) were used. For HP1 detection, mouse monoclonal antibodies against HP1 $\alpha$ (Euromedix, 2HP-1H5 and 2HP2G9), HP1 $\beta$ (Euromedix, 1MOD-1A9), and HP1 $\gamma$ (Euromedix, 2MOD-1G6) were used. We also used different antibodies against mono-, di- and trimethylated H3-K9 gifted by Thomas Jenuwein (IMP, Vienna, Austria), and confirmed the same results.

\section{Immunofluorescence analysis}

Cytospun cells were fixed with $4 \%$ paraformaldehyde for 10 min, permeabilized with $0.1 \%$ Triton $\mathrm{X}-100$ for $10 \mathrm{~min}$, and incubated with the primary antobodies described above at $37^{\circ} \mathrm{C}$ for $40 \mathrm{~min}$. Anti-rabbit IgG or anti-mouse IgG conjugated with Zenon Alexa 568 Fluor (Molecular Probes) were used for detection. The nuclei were counterstained with DAPI, observed under fluorescence microscopy, and analyzed with AxioVision software (Zeiss).

\section{Immunoprecipitation}

For immunoprecipitation of endogenous G9a and GLP, ES cells were harvested with PBS containing trypsin $(0.05 \%)$ and EDTA $(0.2 \mathrm{mM})$. After removing the cytoplasmic fraction with buffer A (10 mM HEPES-KOH at $\mathrm{pH} 7.9,1.5 \mathrm{mM} \mathrm{MgCl}_{2}, 10 \mathrm{mM} \mathrm{KCl}$, $0.5 \mathrm{mM}$ DTT, $10 \mathrm{~min}$ incubation on ice), nuclear pellets were lysed with one $\mathrm{ml}$ of RIPA buffer (PBS containing $1 \%$ Nonidet P-40, $0.5 \%$ deoxycholate, $0.1 \%$ SDS, and protease inhibitor cocktail; Nakalai) for $30 \mathrm{~min}$ at $4^{\circ} \mathrm{C}$ with rotation. Nuclear extracts were then prepared by removing chromatin pellets after centrifugation. Typical conditions for immunoprecipitation were as follows. Nuclear extracts from $10^{7}$ ES cells nuclei were incubated with $2 \mu \mathrm{g}$ of either anti-G9a (\#8620) or anti-GLP (\#422) overnight and immune complexes were collected with 20 $\mu \mathrm{L}$ of protein G slurry (1:1 ratio) for $1 \mathrm{~h}$. The immune complexes were washed three times with $500 \mu \mathrm{L}$ of PBS containing $0.1 \%$ Nonidet P-40. Several murine cells shown in Figure 5C were also treated as described above.

For transient G9a and GLP interaction analyses, HEK293T cells were transfected with combinations of Flag-tagged cDNAs inserted into the pcDNA3 vector (Invitrogen) or the pEGFP-C vectors (Clontech) containing corresponding cDNAs. After $2 \mathrm{~d}$ in culture, whole cell extracts were prepared with RIPA buffer and used for immunoprecipitation as described above. Antibodies used were anti-Myc (9E10), anti-Flag M2 (Sigma), and antiGFP (MBL). EGFP-tagged SET domain-deletion mutants of G9a and GLP were made by removal of cDNA portions coding preSET, SET, and post-SET domains by digestion of restriction enzyme (PmlI for G9a and Scal for GLP) and KpnI. The cDNAs for $\triangle$ SET versions of G9a and GLP encode 936 and 1058 amino acids, respectively.

\section{Immunoblot analyses}

Acid-extracted histones (Tachibana et al. 2002) corresponding to $5 \times 10^{4}$ nuclei were separated by SDS-PAGE, transferred to 
nitrocellulose membranes, blocked with $5 \%$ milk, and probed with the specific antibodies described above. Following washes, blots were incubated with an HRP-conjugated anti-rabbit antibody (Amersham) prior to addition of ECL (Amersham). For detection of the mouse monoclonal primary antibody, we used an HRP-conjugated anti-mouse IgG-Fc portion (Cappel).

\section{In vitro HMTase activity assays}

HMTase activity assays were performed as described (Tachibana et al. 2001).

\section{Chromatin immunoprecipitation}

Chromatin immunoprecipitation analysis was performed as described (Tachibana et al. 2002).

\section{Baculovirus expression}

Insect cells Sf9 were infected with baculovirus encoding either Flag-His-tagged mouse G9a-S or His-tagged GLP cDNA and cell extracts were prepared $2 \mathrm{~d}$ post-infection. Purified protein amounts were measured by coomassie staining in comparison with BSA.

\section{Acknowledgments}

We are particularly grateful to Dr. T. Jenuwein (Vienna IMP) for specific antibodies against mono-, di-, and trimethylated H3-K9. We acknowledge Dr. H. Kimura (Kyoto University) for comments on the cytological analysis and Dr. K. Nishioka (NIG) for PR-Set7 expressing plasmid. We are also grateful to Dr. E.M. Oltz (Vanderbilt University) for critically reading this manuscript. This work was supported by a Grant-in Aid from the Ministry of Education, Science, Technology and Culture of Japan and Uehara Memorial Foundation.

\section{References}

Aagaard, L., Laible, G., Selenko, P., Schmid, M., Dorn, R., Schotta, G., Kuhfittig, S., Wolf, A., Lebersorger, A., Singh, P.B., et al. 1999. Functional mammalian homologs of the Drosophila PEV-modifier Su(var)3-9 encode centromere-associated proteins which complex with the heterochromatin component M31. EMBO J. 18: 1923-1938.

Bannister, A.J., Zegerman, P., Partridge, J.F., Miska, E.A., Thomas, J.O., Allshire, R.C., and Kouzarides, T. 2001. Selective recognition of methylated lysine 9 on histone $\mathrm{H} 3$ by the HP1 chromo domain. Nature 410: 120-124.

Cao, R. and Zhang, Y. 2004a. The functions of E(Z)/EZH2-mediated methylation of lysine 27 in histone H3. Curr. Opin. Genet. Dev. 14: 155-164.

- 2004b. SUZ12 is required for both the histone methyltransferase activity and the silencing function of the EEDEZH2 complex. Mol. Cell 15: 57-67.

Cheutin, T., McNairn, A.J., Jenuwein, T., Gilbert, D.M., Singh, P.B., and Misteli, T. 2003. Maintenance of stable heterochromatin domains by dynamic HP1 binding. Science 299: 721725.

Dodge, J.E., Kang, Y.K., Beppu, H., Lei, H., and Li, E. 2004. Histone H3-K9 methyltransferase ESET is essential for early development. Mol. Cell. Biol. 24: 2478-2486.

Eissenberg, J.C. and Elgin, S.C. 2000. The HP1 protein family: Getting a grip on chromatin. Curr. Opin. Genet. Dev. 10: 204-210.
Eskeland, R., Czermin, B., Boeke, J., Bonaldi, T., Regula, J.T., and Imhof, A. 2004. The N-terminus of Drosophila SU/VAR/3-9 mediates dimerization and regulates its methyltransferase activity. Biochemistry 43: 3740-3749.

Fang, J., Feng, Q., Ketel, C.S., Wang, H., Cao, R., Xia, L., Erdjument-Bromage, H., Tempst, P., Simon, J.A., and Zhang, Y. 2002. Purification and functional characterization of SET8, a nucleosomal histone H4-lysine 20-specific methyltransferase. Curr. Biol. 12: 1086-1099.

Festenstein, R., Pagakis, S.N., Hiragami, K., Lyon, D., Verreault, A., Sekkali, B., and Kioussis, V. 2003. Modulation of heterochromatin protein 1 dynamics in primary mammalian cells. Science 299: 719-721.

Fischle, W., Wang, Y., Jacobs, S.A., Kim, Y., Allis, C.D., and Khorasanizadeh, S. 2003. Molecular basis for the discrimination of repressive methyl-lysine marks in histone $\mathrm{H} 3$ by Polycomb and HP1 chromodomains. Genes \& Dev. 17: 1870-1881.

Gyory, I., Wu, J., Fejer, G., Seto, E., and Wright, K.L. 2004. PRDI-BF1 recruits the histone $\mathrm{H} 3$ methyltransferase G9a in transcriptional silencing. Nat. Immunol. 5: 299-308.

Jenuwein, T. and Allis, C.D. 2001. Translating the histone code. Science 293: 1074-1080.

Lachner, M. and Jenuwein, T. 2002. The many faces of histone lysine methylation. Curr. Opin. Cell Biol. 14: 286-298.

Lachner, M., O'Carroll, D., Rea, S., Mechtler, K., and Jenuwein, T. 2001. Methylation of histone H3 lysine 9 creates a binding site for HP1 proteins. Nature 410: 116-120.

Lachner, M., O'Sullivan, R.J., and Jenuwein, T. 2003. An epigenetic road map for histone lysine methylation. J. Cell Sci. 116: 2117-2124.

Luger, K., Mader, A.W., Richmond, R.K., Sargent, D.F., and Richmond, T.J. 1997. Crystal structure of the nucleosome core particle at 2.8 A resolution. Nature 389: 251-260.

Manzur, K.L., Farooq, A., Zeng, L., Plotnikova, O., Koch, A.W., Sachchidanand, and Zhou, M.M. 2003. A dimeric viral SET domain methyltransferase specific to Lys27 of histone H3. Nat. Struct. Biol. 10: 187-196.

Nishio, H. and Walsh, M.J. 2004. CCAAT displacement protein/cut homolog recruits G9a histone lysine methyltransferase to repress transcription. Proc. Natl. Acad. Sci. 101: 11257-11262.

Nishioka, K., Rice, J.C., Sarma, K., Erdjument-Bromage, H., Werner, J., Wang, Y., Chuikov, S., Valenzuela, P., Tempst, P., Steward, R., et al. 2002. PR-Set7 is a nucleosome-specific methyltransferase that modifies lysine 20 of histone $\mathrm{H} 4$ and is associated with silent chromatin. Mol. Cell 9: 1201-1213.

O'Carroll, D., Scherthan, H., Peters, A.H., Opravil, S., Haynes, A.R., Laible, G., Rea, S., Schmid, M., Lebersorger, A., Jerratsch, M., et al. 2000. Isolation and characterization of Suv39h2, a second histone H3 methyltransferase gene that displays testis-specific expression. Mol. Cell. Biol. 20: 9423 9433.

Ogawa, H., Ishiguro, K., Gaubatz, S., Livingston, D.M., and Nakatani, Y. 2002. A complex with chromatin modifiers that occupies E2F- and Myc-responsive genes in G0 cells. Science 296: $1132-1136$.

Osipovich, O., Milley, R., Meade, A., Tachibana, M., Shinkai, Y., Krangel, M.S., and Oltz, E.M. 2004. Targeted inhibition of V(D)J recombination by a histone methyltransferase. Nat. Immunol. 5: 309-316.

Peters, A.H., O'Carroll, D., Scherthan, H., Mechtler, K., Sauer, S., Schofer, C., Weipoltshammer, K., Pagani, M., Lachner, M., Kohlmaier, A., et al. 2001. Loss of the Suv39h histone methyltransferases impairs mammalian heterochromatin and genome stability. Cell 107: 323-337. 
Peters, A.H., Kubicek, S., Mechtler, K., O'Sullivan, R.J., Derijck, A.A., Perez-Burgos, L., Kohlmaier, A., Opravil, S., Tachibana, M., Shinkai, Y., et al. 2003. Partitioning and plasticity of repressive histone methylation states in mammalian chromatin. Mol. Cell 12: 1577-1589.

Rea, S., Eisenhaber, F., O'Carroll, D., Strahl, B.D., Sun, Z.W., Schmid, M., Opravil, S., Mechtler, K., Ponting, C.P., Allis, C.D., et al. 2000. Regulation of chromatin structure by site-specific histone H3 methyltransferases. Nature 406: 593-599.

Rice, J.C., Briggs, S.D., Ueberheide, B., Barber, C.M., Shabanowitz, J., Hunt, D.F., Shinkai, Y., and Allis, C.D. 2003. Histone methyltransferases direct different degrees of methylation to define distinct chromatin domains. Mol. Cell 12: 1591-1598.

Roopra, A., Qazi, R., Schoenike, B., Daley, T.J., and Morrison, J.F. 2004. Localized domains of g9a-mediated histone methylation are required for silencing of neuronal genes. Mol. Cell 14: 727-738.

Sarraf, S.A. and Stancheva, I. 2004. Methyl-CpG binding protein MBD1 couples histone $\mathrm{H} 3$ methylation at lysine 9 by SETDB1 to DNA replication and chromatin assembly. Mol. Cell 15: 595-605.

Schotta, G., Lachner, M., Sarma, K., Ebert, A., Sengupta, R., Reuter, G., Reinberg, D., and Jenuwein, T. 2004. A silencing pathway to induce $\mathrm{H} 3-\mathrm{K} 9$ and $\mathrm{H} 4-\mathrm{K} 20$ trimethylation at constitutive heterochromatin. Genes \& Dev. 18: 1251-1262.

Schultz, D.C., Ayyanathan, K., Negorev, D., Maul, G.G., and Rauscher III, F.J. 2002. SETDB1: A novel KAP-1-associated histone $\mathrm{H} 3$, lysine 9-specific methyltransferase that contributes to HP1-mediated silencing of euchromatic genes by KRAB zinc-finger proteins. Genes \& Dev. 16: 919-932.

Shi, Y., Sawada, J., Sui, G., Affar el, B., Whetstine, J.R., Lan, F., Ogawa, H., Luke, M.P., and Nakatani, Y. 2003. Coordinated histone modifications mediated by a CtBP co-repressor complex. Nature 422: 735-738.

Strahl, B.D. and Allis, C.D. 2000. The language of covalent histone modifications. Nature 403: 41-45.

Tachibana, M., Sugimoto, K., Fukushima, T., and Shinkai, Y. 2001. Set domain-containing protein, G9a, is a novel lysinepreferring mammalian histone methyltransferase with hyperactivity and specific selectivity to lysines 9 and 27 of histone H3. J. Biol. Chem. 276: 25309-25317.

Tachibana, M., Sugimoto, K., Nozaki, M., Ueda, J., Ohta, T., Ohki, M., Fukuda, M., Takeda, N., Niida, H., Kato, H., et al. 2002. G9a histone methyltransferase plays a dominant role in euchromatic histone H3 lysine 9 methylation and is essential for early embryogenesis. Genes \& Dev. 16: 17791791.

Tanaka, T., Takeno, T., Watanabe, Y., Uchiyama, Y., Murakami, T., Yamashita, H., Suzuki, A., Aoi, R., Iwanari, H., Jiang, S.Y., et al. 2002. The generation of monoclonal antibodies against human peroxisome proliferator-activated receptors (PPARs). J. Atheroscler. Thromb. 9: 233-242.

Turner, B.M. 2000. Histone acetylation and an epigenetic code. Bioessays 22: 836-845.

Wang, H., An, W., Cao, R., Xia, L., Erdjument-Bromage, H., Chatton, B., Tempst, P., Roeder, R.G., and Zhang, Y. 2003. mAM facilitates conversion by ESET of dimethyl to trimethyl lysine 9 of histone $\mathrm{H} 3$ to cause transcriptional repression. Mol. Cell 12: 475-487.

Yagi, T., Tokunaga, T., Furuta, Y., Nada, S., Yoshida, M., Tsukada, T., Saga, Y., Takeda, N., Ikawa, Y., and Aizawa, S. 1993. A novel ES cell line, TT2, with high germline-differentiating potency. Anal. Biochem. 214: 70-76.

Yang, L., Xia, L., Wu, D.Y., Wang, H., Chansky, H.A., Schubach, W.H., Hickstein, D.D., and Zhang, Y. 2002. Molecular clon- ing of ESET, a novel histone H3-specific methyltransferase that interacts with ERG transcription factor. Oncogene 21: $148-152$. 


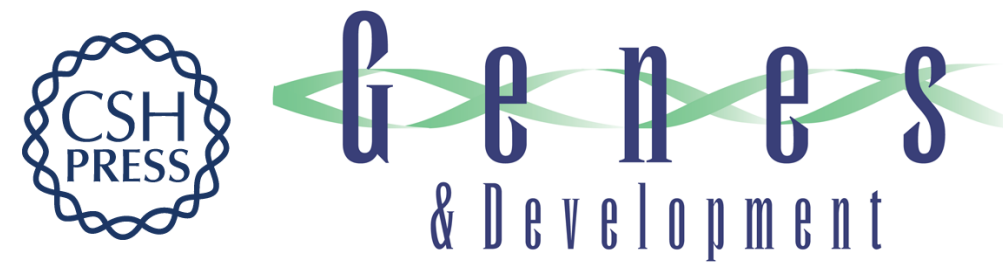

\section{Histone methyltransferases G9a and GLP form heteromeric complexes and are both crucial for methylation of euchromatin at H3-K9}

Makoto Tachibana, Jun Ueda, Mikiko Fukuda, et al.

Genes Dev. 2005, 19:

Access the most recent version at doi:10.1101/gad.1284005

Supplemental http://genesdev.cshlp.org/content/suppl/2005/03/16/gad.1284005.DC1
Material

References This article cites 40 articles, 14 of which can be accessed free at: http://genesdev.cshlp.org/content/19/7/815.full.html\#ref-list-1

License

Email Alerting

Service

Receive free email alerts when new articles cite this article - sign up in the box at the top right corner of the article or click here.

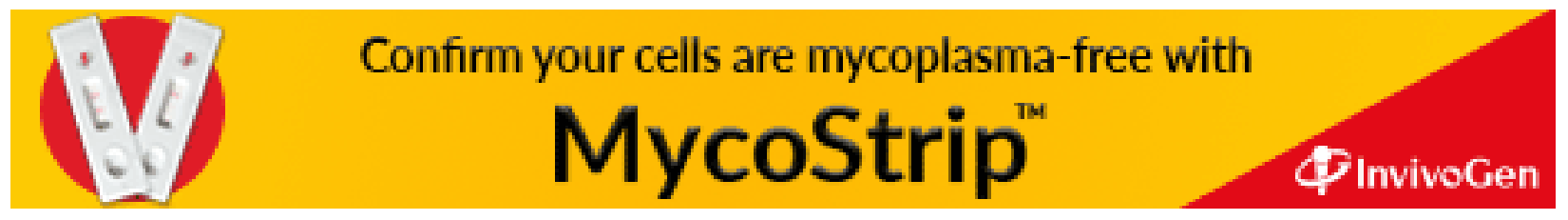

